\title{
FUENTES INTERNACIONALES PARA DETERMINAR LOS DERECHOS DE LAS AUDIENCIAS
}

\author{
International sources when deciding about audience rights
}

Teresita RENDÓN HUERTA BARRERA ${ }^{1}$

\begin{abstract}
Sumario:
Importancia de la comunicación en el proceso de mundialización. II. Las audiencias. III. Fuentes convencionales internacionales para la especificidad de los derechos de las audiencias. IV. Necesidad de profundizar el contenido y el alcance de los derechos colectivos de las audiencias. V. Hacia una guía o referente para la explicitud y reconocimiento de los derechos colectivos de las audiencias. VI. Los Principios ineludibles sobre los que debe construirse el ordenamiento para el ejercicio de los derechos en materia de comunicación. VII. Especificidad de los derechos de las audiencias. VIII. Conclusión. IX. Referencias Bibliográficas. X. Bibliografía. XI. Fuentes convencionales de consulta.
\end{abstract}

Resumen. Este estudio tiene como objetivo central precisar las fuentes convencionales internacionales para la especificidad de los derechos de las audiencia.

Toda persona al entrar en contacto con los medios de comunicación, forma parte de una audiencia y por ese solo hecho debería contar con un sistema de tutela, en razón de que los medios tienen ventajas incomparables sobre los individuos, asumiendo un carácter preponderantemente unilateral al no tener que dar una respuesta inmediata a quien trata de establecer con ellos un vínculo.

Palabras clave: Fuentes convencionales, derecho a la información, libertad de expresión, derechos de las audiencias.

Abstract. This study aims to clarify the central international conventional sources for the specificity of the rights of audience.

Everyone in contact with the media is part of a hearing and for that fact alone should have a system of guardianship, for the reason that the media have unique advantages over individuals, assuming a predominantly unilateral nature not having to give an immediate response to someone trying to establish a link with them.

Keywords: conventional sources, right to information, freedom of expression, rights of audience.

1 Doctora en Derecho por la Universidad Nacional Autónoma de México, con especialidad en Derecho Constitucional y Administrativo. Profesora Investigadora y actualmente Directora de la División de Derecho Política y Gobierno, campus Guanajuato de la Universidad de Guanajuato, México. Autora de las obras Derecho Municipal, Porrúa, México, 2007; Ética del Juzgador, Suprema Corte de Justicia de la Nación, México; Los Conceptos Jurídicos Indeterminados en el Derecho Administrativo, Quito, Ecuador, 2012; Teoría y Técnica de la Reglamentación Municipal en México, Porrúa, 2013. Con nombramiento de Investigador Nacional por el Consejo Nacional de Ciencia y Tecnología de México. Presidenta de la Asociación Internacional de Derecho Municipal, 2013. 


\section{INTRODUCCIÓN}

El ejercicio de la libertad de expresión y el derecho a la información, van operando sobre una serie de disyuntivas y tensiones dialécticas. Bajo la influencia de intereses económicos muy fuertes, surge el imperativo de equilibrar el interés público y el privado, dando nacimiento a "una dimensión individual que impone que los medios de comunicación estén abiertos a todos sin discriminación, así como una dimensión colectiva o social que exige ciertas condiciones respecto de éstos, a fin de que sean verdaderos instrumentos de esa libertad.”

Las empresas concesionarias asumen como principal estrategia maximizar sus ganancias, sin que tengan sentido y cabida asuntos como la educación, la sustentabilidad, los valores, la familia y la ética. La complejidad en gran medida radica en la necesidad de conciliar el interés público y el interés privado en función del mercado.

Estamos inmersos en una dinámica acelerada presidida por una consigna de improvisación, en la que no hemos dado tiempo a que se perfeccionen las ideas, a que se nutra el análisis y esto explica la carencia de una filosofía y de un derecho de la información que vaya al ritmo exigido por los temas universales. Proceso que va contra natura.

Toda persona al entrar en contacto con los medios de comunicación, forma parte de una audiencia y por ese solo hecho debería contar con un sistema de tutela, en razón de que los medios tienen ventajas incomparables sobre los individuos, contando no sólo con una infraestructura comunicativa gigantesca, sino además, asumiendo hasta ahora un carácter preponderantemente unilateral, al no tener que dar una respuesta inmediata a quien trata de establecer con ellos un vínculo.

Abundan al efecto, testimonios centrados en ese fenómeno, como son los miles de mensajes que circulan por Internet a través de Twitter, Facebook u otras redes sociales. Este surgimiento, expresa el anhelo secular de ser escuchado, de ser tomado en cuenta, cargando el acento en los nuevos escenarios.

Otro caso digno de mención, es el sitio YouTube que surgió a la gran audiencia en 2005 y es el fenómeno más grande de la llamada web 2.o. Su impacto no sólo ha repercutido en la web, sino en la propia sociedad. Tanto así que los políticos lo utilizan como un nexo entre ellos y los ciudadanos. El caso más reciente y tal vez más popular, es el del actual presidente de los Estados Unidos de América, Barack Obama, quien utilizó el portal semanalmente para brindar una serie de discursos. En tan solo tres horas de haber sido colgado, el vídeo consiguió más de 500 mil visitas. ${ }^{3}$

El intercambio de información en los medios electrónicos, es tan reciente que nuestras utopías se mezclan con la realidad. Esto explica por qué el derecho de expresión de los medios, los derechos colectivos del público y el derecho a la información, ofrecen condiciones para convertirse en crisol del derecho del futuro. Su previsión legal y reglamentaria, no ha sido considerada como una cuestión de interés general, pero indudablemente se trata de una tarea que deberá estar en las agendas legislativas, a partir de una nueva cultura jurídica de los medios de comunicación.

Tanto el derecho a la información, como la libertad de expresión, son derechos de primera generación, pero su progresiva cobertura permite aludir a los derechos de tipo colectivo, que surgen como resultado de la construcción del discurso social y académico para referirse al

\footnotetext{
2 Análisis de la Acción de Inconstitucionalidad de las Reformas a las leyes de Radio y Televisión y la de Telecomunicaciones, México, 2007, p. 2.

3 CALLEJO, J., Investigar las audiencias: un análisis cualitativo, Paidós, Barcelona, 2001. 
público que imaginariamente interactúa con un medio de comunicación, ya sea radio, cine, televisión, u otros, el cual es, a su vez, quien conforma las diferentes clases de audiencias que dependen de ciertas variables tanto sociológicas, socioeconómicas, como psicológicas del individuo que forma parte de dicha audiencia.

Una consideración sumaria y a priori, podría conducirnos a sostener que no existen derechos del público o audiencia, lo cual es inexacto y apartado de la realidad jurídica, en tanto las fuentes convencionales reconocen múltiples derechos que tocan hasta la esfera de responsabilidad del Estado; que imponen un deber hacer positivo por parte del Estado; y que representan legítimas aspiraciones del individuo como parte de un público que aparentemente es sólo un ente colectivo pasivo, receptor de mensajes a través de un medio de comunicación.

Si bien el titular es el individuo en una comunidad espontánea, no jurídica, es indudable que puede asociarse para su defensa, pretendiendo el reclamo mediato de sus derechos. Pero cuáles son esos derechos? De dónde provienen? Cómo pueden concretarse? Estas son algunas de las interrogantes que han dado cauce a esta investigación.

Falta mucho tiempo para obtener el compromiso del Estado y de las empresas concesionarias, pero un primer paso y el más importante para tener éxito en un programa de protección a los receptores, es el trabajo que llegue a especificar cuáles son esos derechos, de ahí derivarán importantes consecuencias al dotar de entidad a derechos colectivos que se derivan de las fuentes convencionales.

Este estudio tiene como objetivo central coadyuvar a la concreción de tales derechos colectivos, a partir de las razones que justifican su plena e irrevocable inserción en el orden jurídico.

\section{IMPORTANCIA DE LA COMUNICACIÓN EN EL PROCESO DE MUNDIALIZACIÓN}

Las redes de comunicación reestructuran el orden global, de modo que la mundializacion está asociada a este cambio funcional de la comunicación y viceversa. La evolución de la comunicación tiene en la actualidad, un impacto global. Ante la mundialización ${ }^{4}$ de las actividades, la expansión y transformación de la Ciencia jurídica, es un hecho sin precedentes. Si bien, la ley sigue siendo la fuente por excelencia, su interpretación e integración hoy día deben llevarse a cabo sobre un entramado de fuentes plurales, como es el Derecho convencional. La noción tradicional del Derecho, como un sistema formal de coherencia lógica apriorística, como obra sólo del poder legislativo y de la dogmática que representa la lógica deontológica, los principios de temporalidad, jerarquía y especialidad y la deducción como base del razonamiento, son cada vez menos característicos de la realidad jurídica contemporánea, a partir del proceso de erosión que experimentan las fuentes del Derecho. La interpretación y el sistema de fuentes, se han modificado radicalmente en orden a la mundialización, al multiculturalismo y a la diversidad.

La posibilidad de coordinar en tiempo real operaciones que se realizan de forma simultánea a nivel planetario, está transformado la ciencia jurídica. Las tecnologías de la información y de la comunicación - TIC—, han creado un nuevo espacio no territorial que surge y

\footnotetext{
4 V. CASTILLO PERAZA, Carlos, Etcétera, política y cultura en línea, Globalización y mundialización: Sí a la economía de mercado. No, a la mercantilización de la vida social. Disponible en: http://www.etcetera.com. $\mathrm{mx} / 2000 / 364 / \mathrm{ccp} 364 \cdot \mathrm{html}$.
} 
se yuxtapone a la ciudad y a la naturaleza. El desarrollo de nuevos medios de comunicación es un elemento propagador de ideas generadoras de opinión publica.

En los últimos decenios, el proceso de globalización se ha hecho más contundente y acelerado con la extraordinaria movilidad del capital financiero y de las imágenes microelectrónicas, sobre todo al término de la bipolaridad del mundo que suponía la "Guerra Fría".5

En este estado de cosas, sería insensato tratar de sostener la idea decimonónica de un Derecho fundado en el empirismo lógico y en la dogmática kelseniana; rígido, cerrado y excluyente, cuando estamos inmersos en un intercambio progresivo de normas provenientes de la incorporación de los tratados y convenios internacionales, del Derecho de la integración, la mutación del estatuto del poder, la amplia elaboración jurisprudencial, el intercambio de modelos normativos, la revolución de los textos constitucionales con el aporte de los tratados internacionales en materia de derechos fundamentales, la reducción de las cuestiones no judiciables, el Ius Humanitatis o derecho auténticamente global, el imperativo de la interpretación armónica del Derecho convencional, la instauración de sistemas de cooperación entre Estados, el arbitramento internacional, el cambio de modelos tradicionales por esquemas de justicia alternativa, entre otros de los muchos cambios.

No se trata sólo de un proceso económico, sino de la unificación del mundo en todas las actividades. $^{6}$

Los diarios, la radio, la TV, eran locales. Las revistas, el cine y la radio se convirtieron en nacionales, para luego pasar las fronteras y ya en los 80 ser internacionales. En el proceso de comunicación de masas, se traspasan las fronteras del tiempo y del espacio. Los llamados Medios de Comunicación de Masas o Mass Media, son aquellos canales artificiales a través de los cuales se transmiten mensajes dirigidos a un receptor colectivo o social, llamado audiencia.

\section{LAS AUDIENCIAS}

Wicks considera que la audiencia masiva está compuesta por un vasto, anónimo, heterogéneo grupo de individuos y que de esta forma es la manera más simple y rápida de poder clasificarla y segmentarla.7 Señala Huertas Bailén que: "La audiencia es un concepto flexible y cambiante" "el medio de comunicación dominante en cada momento histórico tiene una notable influencia en la concepción general que se tenga de las audiencias". " "La palabra audiencia está familiarmente ligada al término colectivo de "receptores", en el simple modelo secuencial del proceso medios de comunicación masiva." Frases como "distinción cultural", y "especificidad local" se refieren a la cultura sin mancha que se percibe antes de la intrusión de influencias externas. La "conciencia regional" y "las lealtades" siempre describen la iden-

5 MUTSAKU KAMILAMBa, Kande, La globalización vista desde la periferia, México, Tecnológico de Monterrey-Miguel Ángel Porrúa Editores, 2002, p. 7.

6 MORÉ OLIVARES, Elías, Crítica a la globalización y su arquitectura financiera, Economía y Desarrollo, Volumen 3, número 1, marzo 2004, "La globalización no funciona para los pobres, ni para el medio ambiente, ni para la estabilidad económica global. [...] No somos enemigos de la universalidad pero no podemos observar ingenuamente cómo la globalización que pertenece a la humanidad ha sido arrebatada por el capital y en vez de expresarse en términos de igualdad, equidad, se expresa en función del egoísmo.” Pp. 135-137.

7 Wicks, Robert H., Understanding Audiences, 2001, p.14. Versión en línea: http://www.freeebookse.com/ Robert-H-Wicks-PDF4-757569/

8 HUERTAS BAILÉN, A., La audiencia investigada, Barcelona, Gedisa, 2002, p. 18.

9 Callejo, J., Investigar las audiencias: un análisis cualitativo, Barcelona, Paidós, 2001, p.61. 
tidad local. "Un sentido de grupo de pertenecer a una colectividad particular con atributos compartidos (de lugar, idioma, cultura) y un sentido de exclusividad"10. El propio autor refiere que las audiencias son producto del contexto social - que tiene que ver con intereses culturales, información necesitada etc.-

Se define audiencia como: "el público que recibe mensajes a través de un medio de comunicación: sea cine, televisión, radio... El perfil de la audiencia depende de ciertas variables tanto sociológicas como psicológicas: edad, sexo, nivel socioeconómico, hábitos individuales, horarios, aficiones, etc."11

Tipos de audiencia:

"Audiencia potencial: Forma parte de ella todo individuo que sea susceptible de ver un programa de televisión.

Nicho de audiencia: Es una parte de la audiencia potencial que según ciertos precedentes puede aventurarse y que se puede convertir en audiencia real.

Audiencia real: Es el número de personas que siguen un programa.

Índice de audiencia: Es el porcentaje de la audiencia real respecto a la audiencia potencial que podría tener ese programa.

Target: Se corresponde con la audiencia tipo de un programa o por el perfil del espectador buscado por éste.

Cuota de pantalla o share: Es el reparto de las audiencias reales entre todos los canales expresado en porcentajes." 12

El presente trabajo no es una simple digresión sin consecuencias prácticas, en tanto que existen múltiples formas de lesionar los derechos de las audiencias, ya sea indirectamente con la formación de estereotipos nocivos, o directamente mediante hechos que afectan la veracidad o totalidad de la información: la censura y la manipulación de la información.

Con relación a los estereotipos, implica una visión uniforme de determinado grupo, que excluye las diferencias individuales entre sus integrantes. Es importante considerar que por medio de los estereotipos se van creando actitudes de intolerancia por la diversidad y formando múltiples prejuicios. "El estereotipo como creencia puede llevar al prejuicio como actitud y puede producir discriminación como comportamiento. Los estereotipos se consideran el componente cognitivo de una actitud particular y se elaboran a partir de mecanismos cognitivos que simplifican la realidad, por razones de economía del esfuerzo mental y por ello presentan el peligro de la distorsión." ${ }^{13}$ La publicidad usa gran cantidad de estereotipos, ya que lo único que busca es el consumo, presentando modelos - de excelente presen-

\footnotetext{
${ }^{10}$ MCQUAIL, Denis. Media Performance, Londres, Sage, 1992, p. 264.

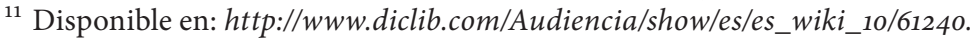

${ }^{12}$ Disponible en: Audiencia_\%28televisi\%C3\%B3n\%29.

${ }^{13}$ DEL RÍO, Rosalía. Pedagogía de la Diversidad. Disponible en: eduso.files.wordpress.com/20o8/o6/tema-31-diversidad.pdf.
} 
cia, que se identifican por su delgadez, rasgos finos, ojos claros, ropa cara, etc.- - que indican en lo que hay que gastar y qué hay que hacer.

Se ejerce la censura por motivos religiosos, económicos, políticos, sociales o religiosos, a fin de vetar ciertos contenidos, lo cual determina que quienes accedan a la información que presenta un medio que ha practicado la censura, no cuenten con todos los elementos de juicio para formarse una opinión objetiva. En el caso de la manipulación de la información, ésta se interviene para beneficiar una posición determinada, operándose la interpretación de lo sucedido a conveniencia de determinados intereses, mediante una organización tramposa de la información, de tal forma que se logra crear en la mente del receptor, la lectura que el medio pretende.

Dado que la mayoría de estudios sobre las audiencias se encuentran vinculados a temas de mercadotecnia y economía, ${ }^{14}$ considero indispensable un abordaje jurídico, a partir de las fuentes convencionales.

III. FUENTES CONVENCIONALES INTERNACIONALES PARA LA ESPECIFICIDAD DE LOS DERECHOS DE LAS AUDIENCIAS

Por lo general, los tratados incorporados al orden jurídico de cada país que los suscribe, aportan soluciones más evolucionadas que las tradicionalmente establecidas en el derecho interno, con la característica de que las fuentes internacionales son más armónicas y avanzadas. En materia del derecho a la información y del de libertad de expresión, existen múltiples declaraciones vinculatorias y decisiones que reconocen a ambos como derechos humanos fundamentales, en que se fundamenta en el reconocimiento constitucional que los países han hecho de estos derechos, aquí se hace una somera referencia a los más importantes.

En 1946, la Asamblea General de la Organización de las Naciones Unidas (ONU) adoptó la Resolución 59, en la que estableció: "La libertad de información es un derecho humano fundamental y... la piedra angular de todas las libertades a que la ONU está consagrada". ${ }^{15}$

La Declaración Universal de los Derechos Humanos (DUDH), adoptada por la Asamblea General de la ONU en 1948, considerada la declaración por excelencia sobre derechos humanos internacionales, en sus artículos 19 y 29, respectivamente establece:

"Artículo 19. Todo individuo tiene derecho a la libertad de opinión y de expresión; este derecho incluye el de no ser molestado a causa de sus opiniones, el de investigar y recibir informaciones y opiniones, y el de difundirlas, sin limitación de fronteras, por cualquier medio de expresión.

Artículo 29. 2. En el ejercicio de sus derechos y en el disfrute de sus libertades, toda persona estará solamente sujeta a las limitaciones establecidas por la ley con el único fin de asegurar el reconocimiento y el respeto de los derechos y libertades de los demás, y de satisfacer las justas exigencias de la moral, del orden público y del bienestar general en

\footnotetext{
${ }^{14}$ Internet ha sido desde sus inicios el medio que mejor se ha estudiado, en términos de medición de la audiencia y la eficacia de la comunicación publicitaria.

1514 de diciembre de 1946.

CienCIA JuRÍDICA. Departamento de Derecho. División de Derecho Política y Gobierno, Universidad de Guanajuato - Año 1, No. 4, 2013
} 
una sociedad democrática. 3. Estos derechos y libertades no podrán en ningún caso ser ejercidos en oposición a los propósitos y principios de las Naciones Unidas." 16

El Pacto Internacional de Derechos Civiles y Políticos (PIDCP), de observancia obligatoria, fue adoptado por la Asamblea General de las Naciones Unidas en 1966 y en sus artículos 19 y 20 se señala:

“Artículo 20.

1. Nadie podrá ser molestado a causa de sus opiniones.

2. Toda persona tiene derecho a la libertad de expresión; este derecho comprende la libertad de buscar, recibir y difundir informaciones e ideas de toda índole, sin consideración de fronteras, ya sea oralmente, por escrito o en forma impresa o artística, o por cualquier otro procedimiento de su elección.

3. El ejercicio del derecho previsto en el párrafo 2 de este artículo entraña deberes y responsabilidades especiales. Por consiguiente, puede estar sujeto a ciertas restricciones, que deberán, sin embargo, estar expresamente fijadas por la ley y ser necesarias para:

a) Asegurar el respeto a los derechos o a la reputación de los demás;

b) La protección de la seguridad nacional, el orden público o la salud o la moral públicas.

Artículo 20

1. Toda propaganda en favor de la guerra estará prohibida por la ley.

2. Toda apología del odio nacional, racial o religioso que constituya incitación a la discriminación, la hostilidad o la violencia estará prohibida por la ley.” ${ }^{17}$

La Convención Americana sobre Derechos Humanos (CADH), de observancia obligatoria, garantiza la libertad de expresión, al prever:

\section{“Artículo 13}

1. Toda persona tiene derecho a la libertad de pensamiento y de expresión. Este derecho comprende la libertad de buscar, recibir y difundir informaciones e ideas de toda índole, sin consideración de fronteras, ya sea oralmente, por escrito o en forma impresa o artística, o por cualquier otro procedimiento de su elección.

2. El ejercicio del derecho previsto en el inciso precedente no puede estar sujeto a previa censura sino a responsabilidades ulteriores, las que deben estar expresamente fijadas por la ley y ser necesarias para asegurar:

a. el respeto a los derechos o a la reputación de los demás, o

\footnotetext{
${ }_{16}$ Resolución 217 A (III), 10 de diciembre de 1948.

${ }^{17}$ Artículo 19. Resolución 2200 A (XXI), 16 de diciembre de 1966, en vigor desde el 23 de marzo de 1976.
} 
b. la protección de la seguridad nacional, el orden público o la salud o la moral públicas.

3. No se puede restringir el derecho de expresión por vías o medios indirectos, tales como el abuso de controles oficiales o particulares de papel para periódicos, de frecuencias radioeléctricas, o de enseres y aparatos usados en la difusión de información o por cualesquiera otros medios encaminados a impedir la comunicación y la circulación de ideas y opiniones.

4. Los espectáculos públicos pueden ser sometidos por la ley a censura previa con el exclusivo objeto de regular el acceso a ellos para la protección moral de la infancia y la adolescencia, sin perjuicio de lo establecido en el inciso 2.

5. Estará prohibida por la ley toda propaganda en favor de la guerra y toda apología del odio nacional, racial o religioso que constituyan incitaciones a la violencia o cualquier otra acción ilegal similar contra cualquier persona o grupo de personas, por ningún motivo, inclusive los de raza, color, religión, idioma u origen nacional.

\section{Artículo 14. Derecho de Rectificación o Respuesta}

1.Toda persona afectada por informaciones inexactas o agraviantes emitidas en su perjuicio a través de medios de difusión legalmente reglamentados y que se dirijan al público en general, tiene derecho a efectuar por el mismo órgano de difusión su rectificación o respuesta en las condiciones que establezca la ley.

2. En ningún caso la rectificación o la respuesta eximirán de las otras responsabilidades legales en que se hubiese incurrido.

3. Para la efectiva protección de la honra y la reputación, toda publicación o empresa periodística, cinematográfica, de radio o televisión tendrá una persona responsable que no esté protegida por inmunidades ni disponga de fuero especial". ${ }^{18}$

Declaración Americana de los Derechos y Deberes del Hombre.

"Artículo IV

Toda persona tiene derecho a la libertad de investigación, de opinión y de expresión y difusión del pensamiento por cualquier medio". ${ }^{19}$

El Consejo Europeo (CE) siendo una organización intergubernamental, integrada por 43 Estados miembros, promueve los derechos humanos, la educación y la cultura. Uno de sus documentos esenciales es la Convención Europea sobre Derechos Humanos (CEDH),

\footnotetext{
${ }^{18}$ Adoptada en San José, Costa Rica, el 22 de noviembre de 1969, en vigor desde el 18 de julio de 1978. La Corte Interamericana de Derechos Humanos, interpretando el artículo 13, reconoció la libertad de información como un derecho humano fundamental, tan importante para una sociedad libre como la libertad de expresión.

${ }^{19}$ Aprobada en la Novena Conferencia Internacional Americana, en Bogotá, Colombia, en 1948. 
la cual garantiza en su artículo 10, la libertad de expresión e información como derecho humano fundamental. ${ }^{20}$

La Commonwealth ${ }^{21}$, es una asociación voluntaria de 54 países en razón de vínculos históricos, marcos legislativos e institucionales comunes y valores compartidos, ha tomado decisiones importantes en función de reconocer a los derechos humanos y a la democracia como componentes fundamentales en su estructura. En 1991, adoptó la Declaración Commonwealth Harare, misma que destacó sus valores políticos fundamentales, incluyendo el respeto a los derechos humanos y el derecho inalienable y democrático de todo ciudadano a participar en el desarrollo de su sociedad. ${ }^{22}$

En el Artículo 13 de la "Convención sobre los Derechos del Niño" ${ }_{23}$

“1. El niño tendrá derecho a la libertad de expresión; ese derecho incluirá la libertad de buscar, recibir y difundir informaciones e ideas de todo tipo, sin consideración de fronteras, ya sea oralmente, por escrito o impresas, en forma artística o por cualquier otro medio elegido por el niño.

2. El ejercicio de tal derecho podrá estar sujeto a ciertas restricciones, que serán únicamente las que la ley previa y sean necesarias:

a) Para el respeto de los derechos o la reputación de los demás; o

Para la protección de la seguridad nacional o el orden público o para proteger la salud o la moral públicas."

La Convención Internacional sobre la Eliminación de todas las Formas de Discriminación Racial, refiere en su Artículo 4:

Los Estados partes condenan toda la propaganda y todas las organizaciones que se inspiren en ideas o teorías basadas en la superioridad de una raza o de un grupo de personas de un determinado color u origen étnico, o que pretendan justificar o promover el odio racial y la discriminación racial, cualquiera que sea su forma, y se comprometen a tomar medidas inmediatas y positivas destinadas a eliminar toda incitación a tal discriminación o actos de tal discriminación, y, con ese fin, teniendo debidamente en cuenta los principios incorporados en la Declaración Universal de Derechos Humanos, así como los derechos expresamente enunciados en el artículo 5 de la presente Convención, tomarán, entre otras, las siguientes medidas:

a) Declararán como acto punible conforme a la ley toda difusión de ideas basadas en la superioridad o en el odio racial, toda incitación a la discriminación racial, así como todo acto de violencia o toda incitación a cometer tales actos contra cualquier raza o grupo de

\footnotetext{
${ }^{20}$ E.T.S. núm. 5, adoptada el 4 de noviembre de 1950, en vigor desde el 3 de septiembre de 1953.

${ }^{21}$ La Mancomunidad Británica de Naciones, normalmente se conoce como la Comunidad y antiguamente era conocida como la Commonwealth británica, es una organización intergubernamental, en la cual todos los miembros excepto en Mozambique y Ruanda, fueron parte del Imperio Británico.

${ }^{22}$ Reunión de los jefes de Estado del Commonwealth, 20 de octubre de 1991, secciones 4 y 9. Ver también el Programa de Acción Millbrook Commonwealth, reunión de los jefes de Estado del Commonwealth, 12 de noviembre de 1995 .

${ }^{23}$ Convención sobre los Derechos del Niño por la Asamblea General de las Naciones Unidas el 20 de noviembre de 1989.
} 
personas de otro color u origen étnico, y toda asistencia a las actividades racistas, incluida su financiación;

b) Declararán ilegales y prohibirán las organizaciones, así como las actividades organizadas de propaganda y toda otra actividad de propaganda, que promuevan la discriminación racial e inciten a ella, y reconocerán que la participación en tales organizaciones o en tales actividades constituye un delito penado por la ley;

En el ámbito espacial y temporal de la globalización de las comunicaciones, ante un receptor colectivo y heterogéneo en su nivel cultural, social, económico, político o religioso, resulta complejo precisar jurídicamente el derecho o conjunto de derechos que son oponibles por ese espectador pasivo o selectivo. Pero la protección y garantía de los derechos humanos establecidos en fuentes convencionales internacionales, en materia de libertad de expresión y de derecho a la información, constituyen una obligación jurídica. Tales derechos son aplicables a las audiencias, aun cuando a través de los medios se genera una comunicación que es fundamentalmente unidireccional, es decir, no es posible la reacción inmediata de los receptores ante lo expuesto por el emisor, pero ello no significa que si se trastocan sus derechos, deban quedar indemnes.

IV. NECESIDAD DE PROFUNDIZAR EL CONTENIDO Y EL ALCANCE DE LOS DERECHOS COLECTIVOS DE LAS AUDIENCIAS

La ausencia de una definición universalmente admitida de tales derechos, pone de manifiesto el escaso interés que suele concedérsele al tema. Los derechos colectivos e individuales de los destinatarios, deben ser reconocidos y garantizados en el marco de la Constitución, de la ley y del respeto al orden público por cada Estado. Pero ¿cómo lograrlo?

No se requieren teorizaciones sesgadas, basta con que se atienda desde la óptica de las fuentes convencionales internacionales, de los derechos humanos, de los derechos colectivos, buscando que sean reconocidos, respetados y garantizados por el Estado contemporáneo como protagonista de la libertad, la democracia, la justicia, la seguridad y el bienestar social, cuya realización es su razón de ser. Valores y funciones mucho más importantes que la estructura política o el mero ejercicio del poder. Esos valores son contenido, lo orgánico y lo político son mero continente.

A pesar de los obstáculos e incluso de la franca oposición que ejercen los dueños de los medios, deberá conseguirse el pleno reconocimiento de los derechos en estudio. Sería una salida simplista, ilusoria y desacertada reducir la solución a la mera enunciación de esos derechos, apostándole sólo a la emisión de un decreto legislativo. Deberán crearse además, las instancias y los instrumentos jurídicos para su protección, deberá, asimismo, diseñarse un sistema normativo de tutela efectiva.

V. HACIA UNA GUÍA O REFERENTE PARA LA EXPLICITUD Y RECONOCIMIENTO DE LOS DERECHOS COLECTIVOS DE LAS AUDIENCIAS

Que prospere la previsión legal del derecho de las audiencias, en el orden nacional, supone entre muchas otras acciones, primeramente una conciencia, la definición de principios sen- 
cillos e indiscutibles sobre los cuales se sustente el diseño de las normas jurídicas sustantivas, orgánicas, procedimentales, procesales y sancionatorias, centradas en la tutela integral.

Para asegurar tales derechos, deberá darse una protección in genere a ese público con un carácter no territorial ni permanente, con referencias comunes a una cultura, compuesto por personas con variedad de gustos, edades, género, creencias, intereses, cultura y aficiones, a esos sujetos unidos temporalmente por su disposición a recibir un mensaje, en tanto comparten ciertos gustos o predilecciones.

Para hacer realidad esa defensa, el orden jurídico debe contar con un sistema que responda con calidad a las necesidades y expectativas de las audiencias, que amplíe sus posibilidades de elección, que cuente con medios alternativos para la solución de conflictos, con instancias eficaces para la presentación de quejas, resolución de litigios y con mecanismos de participación ciudadana. En ese sentido, debe establecerse como conditio sine qua non, su imprescriptibilidad, su permanencia, y que para su litigación o su defensa, no se requieran necesariamente los servicios de un abogado.

VI. LOS PRINCIPIOS SOBRE LOS QUE DEBE CONSTRUIRSE EL ORDENAMIENTO PARA EL EJERCICIO DE LOS DERECHOS EN MATERIA DE COMUNICACIÓN

Los principios ineludibles sobre los que debe construirse el ordenamiento para el ejercicio de los derechos en materia de comunicación son:

1. Acceso plural a las frecuencias del espectro radioeléctrico, dado que: "Las asignaciones de radio y televisión deben considerar criterios democráticos que garanticen una igualdad de oportunidades para todos los individuos en el acceso a los mismos". ${ }^{24}$

2. Cumplimiento de convenciones, pactos y tratados internacionales relativos a los derechos fundamentales de información, asociación, educación y libre expresión.

3. Veracidad, contra el engaño y la manipulación.

4. Producción independiente que desarrolle enfoques plurales.

5. Reducción de los márgenes de discrecionalidad y establecimiento de facultades regladas para las autoridades que otorgan permisos, licencias, concesiones o autorizaciones en materia de medios de comunicación.

6. Simplificación administrativa.

7. Transparencia en los procesos de otorgamiento de permisos, licencias, concesiones o autorizaciones en materia de medios de comunicación.

8. Contralorías ciudadanas para la vigilancia de la correcta aplicación de la legislación en materia de medios.

\footnotetext{
${ }^{24}$ Artículo 12 de la Declaración de Principios sobre Libertad de Expresión, Comisión Interamericana de Derechos Humanos, 2000.
} 
9. Fortalecimiento de la responsabilidad de los servidores públicos ante acciones y omisiones en el ejercicio de sus atribuciones en materia de medios de comunicación.

10. Creación del Ombudsman de la comunicación.

\section{ESPECIFICIDAD DE LOS DERECHOS DE LAS AUDIENCIAS}

Tratando de acercarnos a un desglose y concreción de los derechos consagrados en las fuentes convencionales internacionales, propongo como derechos de toda audiencia:

1. Exigir el respeto a la dignidad de la persona en el ejercicio de sus derechos en materia de comunicación.

2. Ejercer plenamente su derecho a elegir tanto los medios como los contenidos que más le satisfagan, decisión que debe recaer finalmente en el individuo, en el ciudadano, no en el gobierno ni en los dueños de los medios.

3. Reclamar objetividad y verdad en los contenidos de la información.

4. Ejercer el derecho a ser escuchado.

5. El derecho a la verdad.

6. Recibir una programación que promueva la paz, la salud, la tolerancia, el multiculturalismo, la igualdad, el pluralismo, la inclusión y la solidaridad.

7. Ejercitar el derecho de réplica.

8. Participar en la formación de contenidos.

9. Recibir transmisiones conforme a los avances tecnológicos, del progreso científico y de todos los demás factores que constituyen el patrimonio común de la humanidad.

10. Acceder a programaciones de calidad.

11. Sugerir prioridades en lo que atañe al desarrollo de planes, proyectos y programas de mejora de medios.

12. Exigir que se promueva a través de los medios, la solidaridad, que comporta la mutua cooperación entre los pueblos, con base en el respeto y en la aplicación del principio de reciprocidad.

13. Identificarse, organizarse y afirmarse como audiencia, sin que alguna instancia pueda limitar este derecho.

14. Exigir contenidos adecuados para los niños y respeto a los horarios.

15. Manifestar la voluntad colectiva en forma imprescriptible e inalienable. 
16. Mantener, desarrollar y fortalecer sus predilecciones.

17. Buscar que a través de los medios se difundan los valores, el arte, las tradiciones y la cultura universal.

18. Oponerse a todo contenido que comprometa la sustentabilidad, que promueva las desigualdades, la guerra, la manipulación, las discriminaciones y todo tipo de crueldad.

19. Ser consultada y encuestada sobre contenidos de la programación y prospecciones.

20. Promover prácticas que fomenten la diversidad, la civilidad y la sustentabilidad.

21. Desarrollar formas de interacción mediática y de convivencia social.

22. Fomentar la valoración y conservación del patrimonio natural, histórico, artístico y cultural de cada país.

23. Que a tavés de los medios se contribuya a la formación de valores cívicos.

24. Llevar a cabo gestiones de mejora de los medios, mediante representantes, ante los organismos que determine la ley.

25. Ejercer su derecho de agruparse y de explotar su poder para lograr una relación equilibrada con los medios de comunicación y con el Estado.

26. Acceder equitativamente a los beneficios que otorgue el Estado para el desarrollo de los medios.

27. Contar con leyes e instituciones nacionales que tutelen los derechos de los usuarios de los medios de comunicación.

28. Acceder a la jurisdicción para resolver posibles las violaciones.

29. Luchar contra manipulación, el engaño y la censura.

30. Recibir indemnizaciones por impactos negativos o afectaciones de los medios.

VIII. CONCLUSIÓN

Hasta ahora los derechos de las audiencias están a merced de los poderes económicos y estatales, su contenido es difuso, pero como no se trata de un asunto menor, ni de un concepto estático y simple, invariablemente deberá estar en construcción, deberá, asimismo, dotársele de un contenido preciso en el ordenamiento jurídico de cada país, tomando como base las fuentes convencionales internacionales, con el fin de institucionalizar su defensa y garantizar su ejercicio. 
IX. BIBLIOGRAFÍA

CALLEJO, J., Investigar las audiencias: un análisis cualitativo, Paidós, Barcelona, 2001.

CASTILLO PERAZA, Carlos, "Globalización y mundialización: Sí a la economía de mercado. No, a la mercantilización de la vida social.” Etcétera, política y cultura en línea, México, 1988.

DEL RÍO, Rosalía, 2008, Pedagogía de la Diversidad. Disponible en: eduso.files.wordpress. com/2008/06/tema-31-diversidad.pdf.

HUERTAS BAILÉN, A., La audiencia investigada, Gedisa, Barcelona, 2002.

MCQUAIL, Denis, Media Performance, Sage, Londres, 1992.

MORÉ OLIVARES, Elías, “Crítica a la globalización y su arquitectura financiera”, Economía y Desarrollo, Volumen 3, número 1, Colombia, 2004.

MUTSAKU KAMILAMBA, Kande, La globalización vista desde la periferia, Tecnológico de Monterrey-Miguel Ángel Porrúa Editores, México, 2002.

WICKS, ROBERT H., 2001, Understanding Audiences. Versión en línea: http://www.freeebookse.com/Robert-H-Wicks-PDF4-757569/

\section{FUENTES CONVENCIONALES DE CONSULTA}

Convención Americana sobre Derechos Humanos (CADH), José de Costa Rica el 22 de noviembre de 1969.

Convención Europea sobre Derechos Humanos (CEDH), se firmó en Roma el 4 de noviembre de 1950.

Convención Internacional sobre la Eliminación de todas las Formas de Discriminación Racial, Adoptada y abierta a la firma y ratificación por la Asamblea General en su Resolución 2106 A (XX), de 21 de diciembre de 1965.

Convención sobre los Derechos del Niño. Asamblea General Naciones Unidas, 20 de noviembre de 1989.

Declaración Americana de los Derechos y Deberes del Hombre (DADDH), aprobada por la Conferencia Internacional Americana realizada en Bogotá en 1948.

Declaración Commonwealth Harare,1991.

Declaración Universal de los Derechos Humanos (DUDH), adoptada por la Asamblea General de la ONU en 1948.

Pacto Internacional de Derechos Civiles y Políticos (PIDCP), adoptado por la Asamblea General de las Naciones Unidas en 1966.

Resolución 59 de la Asamblea General de la Organización de las Naciones Unidas (ONU) de 1946. 